\title{
The bitumen microstructure: a fluorescent approach
}

\author{
Florian Handle $\cdot$ Josef Füssl · Susanna Neudl • Daniel Grossegger • \\ Lukas Eberhardsteiner · Bernhard Hofko • Markus Hospodka • Ronald Blab • \\ Hinrich Grothe
}

Received: 11 August 2014/ Accepted: 28 November 2014/Published online: 7 December 2014

(C) RILEM 2014

\begin{abstract}
Five bituminous samples were carefully studied by confocal laser scanning microscopy using $488 \mathrm{~nm}$ excitation radiation and observing 500-530 nm of emission. The images revealed the microstructure of bitumen. The influence of the admixture of mineral aggregates concerning the microstructure was tested. For the minerals, no significant influence was found. For understanding the origin of fluorescent signals, the samples were separated into asphaltenes and maltenes and analyzed with fluorescence spectroscopy. Although former works have assumed the origin of fluorescent emissions in bitumen to be found in the asphaltene fraction, the asphaltenes produce little to no emissions, but the maltenes exhibit strong fluorescence in the observed spectral region. For deeper insight, fractionation of the bitumina into the SARA fractions by chromatographic column separation was necessary. The fluorescence spectra of these fractions were analyzed
\end{abstract}

F. Handle · S. Neudl · D. Grossegger · H. Grothe ( $\square)$ Institute of Materials Chemistry (E165), Vienna University of Technology, Getreidemarkt 9/BC/01, 1060 Vienna, Austria

e-mail: grothe@tuwien.ac.at

J. Füssl

Institute for Mechanics of Materials and Structures, Vienna University of Technology, Karlsplatz 13, 1040 Vienna, Austria

L. Eberhardsteiner - B. Hofko - M. Hospodka - R. Blab Institute of Transportation, Vienna University of Technology, Gußhausstrasse 28-30, 1040 Vienna, Austria and revealed the aromatics and resin phases to be the only components capable of sufficiently intense fluorescent emission. This is a strong argument for a complex internal microstructure consisting of a mantle of aromatics surrounding an inner core.

Keywords Bitumen - Microstructure · Photoluminescence spectroscopy $\cdot$ Optical microscopy

\section{Introduction}

Since the times of ancient Babylon, bitumen has been used in road engineering and construction [1, 17]. Today it is one of the primary construction materials in road engineering. About $95 \%$ of the world production of bitumen (approximately $100 \mathrm{Mt} / \mathrm{year}$ ) are used by the pavement industry as asphalt mixtures [27]. The mechanical properties of asphalt mixtures can be assessed through a multi-scale modelling approach [24, 42, 43]. The primary assumption of multi-scale analysis is that the material properties of the composite can be calculated, if the properties of the basic materials are known and the microstructure of the composite is understood. Hence, the microstructure of bitumen plays a crucial role.

As every bitumen is a very complex material and the properties tend to vary dependent on source, production cycle, additives, and additional chemical- 
physical treatments, bitumen according to European regulations is described simply as a "virtually involatile, adhesive and waterproofing material derived from crude petroleum or present in natural asphalt, which is completely or nearly completely soluble in toluene, and very viscous or nearly solid at room temperature" [10]. Due to its limited economic importance, most research excludes the natural asphalt, because most bitumen used nowadays is obtained as the residue of the vacuum distillation in the refinery process of crude oil [26].

The complex chemical nature of bitumen complicates many analytic methods to the limit of applicability. A widely accepted analytical approach is to separate bitumen according to similar chemical behavior into a saturated, an aromatic, a resin, and an asphaltene fraction (SARA). The asphaltene fraction is hereby defined as the $n$-heptane insoluble and toluene soluble part of bitumen, while the soluble fractions are called maltenes. Maltenes can then be separated by column chromatography [4, 9, 27]. To avoid confusion, the SARA nomenclature was preferred to the Corbett and ASTM nomenclatures [4, 9]. Hence, aromatics refer to naphthenic aromatics and resins to polar aromatics in the ASTMStandard [41]. Although concerns regarding repeatability of the chromatographic separation process have been raised, it is still the most validated and practical separation technique for bitumen [37]. The rheological properties of bitumen can be explained by various modelling approaches [27]. However, contemporary research has all but eliminated single phase approaches, by providing solid evidence that bitumen has indeed a definite microstructure that can be measured and visualized by various techniques. Small angle X-ray scattering (SAXS) and small angle neutron scattering (SANS) experiments have proven beyond doubt that ordered structures in bitumen exist [12, 13, 44, 48, 59]. Atomic force microscopy (AFM) and scanning electron microscopy (SEM) have revealed a morphology of characteristic and reproducible appearance, which is often described as "bee-like" structures of 1-5 $\mu \mathrm{m}[8,15,27,28,30$, 35, 36, 38, 51, 53, 60, 61]. Confocal laser scanning microscopy (CLSM) has uncovered the existence of fluorescent centers in bitumen of $1-10 \mu \mathrm{m}$ size, indicating high concentrations of fluorescent species in definite volume elements evenly dispersed through the material $[5,33]$. Since both structures range in the same order of magnitude, it can reasonably be assumed that they are identical or at least strongly linked to each other. The combination of physicochemical analysis and rheological data concludes the existence of at least two separate phases in bitumen. The identification of these structures and the investigation of their properties are currently in the focus of the scientific community [27, 60].

After decades of research, the ideas of the micelle theory still form the basis of one of the two major models for bitumen microstructure [27, 45]. Asphaltenes are thought to agglomerate to form kind of micelle like structures surrounded by other high-polar material and dispersed through the maltene phase [40, 52]. This model is strongly supported by the distinctive agglomeration behaviour of asphaltenes, which also aggregate in crude oil and most pure solvents [59]. This explains the structural investigations as well as the rheological properties of bitumen as a highly viscous visco-elastic material [27]. Basically, the model assumes the aggregation of asphaltene micelles into larger structures of around 1-20 $\mu \mathrm{m}$. Typically, these structures are in the range of a microcapsule by IUPAC definitions, which is essentially a core-shell particles with a diameter of around 0.1-100 $\mu \mathrm{m}$ [50] as opposed to micelles, which are generally considered to be much smaller. However, the use of the term "micelle" for these "super-micelles" can be attributed to the cross-linking between them and the asphaltene micelle model (e.g. in [5]).

The second model explains the expression of structural features in the $\mu \mathrm{m}$ range on the bitumen surface as the crystallization of waxes. This argumentation is based on several studies, which prove a strong correlation between wax/saturates content and the frequency of occurrence of structural features [27, 33, 51]. Key works in this area have been conducted by Redelius [46]. Additionally, mixed models have developed by combining both asphaltene precipitation and wax crystallization approaches [53].

CLSM is capable of analyzing highly localized fluorescence emission and allows the detailed investigation of the bitumen scale of asphalt observation [24]. This can be used to efficiently visualize the microstructure of bitumen [5, 18, 21, 33] and structural effects of bitumen modification [14, 29, 47, 54]. Bearsley et al. presented a very detailed comparison of CLSM with other imaging techniques [5]. In general, the fluorescent centers are 
interpreted as asphaltene micelles. Previous works relied heavily on CLSM images for the identification of the fluorescent phase [5]. However, CLSM can only provide leads and indications, but is not suited to determine fluorescence characteristics of molecules or composites. Fluorescence spectroscopy can be used to study aromatic and conjugated carbohydrates, as the capability of electronic transitions that decay emitting a photon is almost exclusive to these classes of molecules [25, 49]. Fluorescence spectroscopic studies of bitumen and bitumen fractions can provide a solid base for the identification of these structures $[16,56]$.

Although adhesion between mineral aggregates and bitumen is a major topic in materials research $[6,7,22$, $24,31,57]$, CLSM has not been used yet to investigate bitumen/mineral aggregate mixtures. Comparing five different bitumina by CLSM we were able to monitor the dependence of the microstructure on the phase composition. The focus was on the bitumen scale, when CLSM can be employed on bitumen and filler mixtures, providing information about the changes in microstructure induced by the admixture of the mineral phase.

\section{Methods}

\subsection{Materials}

Five different bitumina and bitumen precursors were provided by OMV AG obtained from vacuum distillation. The samples were classified and named by their needle penetration value. The first is 50/70 bitumen ready for use in asphalt mix production. Two soft bitumina 70/100A and 70/100B, typically used in the production of polymer modified bitumen were investigated. PE1005 is a bitumen precursor and is a vacuum flashed and cracked vacuum residuum. The samples were chosen for their practical relevance mostly. 50/70 is commonly used in road engineering and $70 / 100 \mathrm{~A}$ and $\mathrm{B}$ are the precursors for SBS modified bitumina often used in high performance roads. All samples were stored in sealed metal cans to avoid ageing. All solvents used in the experiments were obtained from Carl Roth Gmbh+Co. KG and of ROTIPURAN quality ( $\geq 99 \%$ p.a.). The aluminum oxide used in the chromatographic column had a grain size of 63-200 $\mu \mathrm{m}$ and $\mathrm{pH}$ value of 3.5-4.5.

\subsection{Separation and fractionation}

The separation of bitumen into four major fraction was conducted on the basis of the ASTM Standard 4124, but slightly modified to allow a more differentiated analysis of the material (see Fig. 1) [4]. Around $10 \mathrm{~g}$ $( \pm 1 \mathrm{~g})$ of bitumen was placed in a $2 \mathrm{~L}$ Erlenmeyer flask and $n$-heptane was added at a ratio of $30 \mathrm{~mL}$ per $\mathrm{g}$ of bitumen. Then the Erlenmeyer flask was put onto a heating plate and heated under stirring to $90{ }^{\circ} \mathrm{C}$. The mixture was stirred until no bitumen sticking to the bottom of the flask. Afterwards, stirring and heating was continued for another $1.5 \mathrm{~h}$. The flask was removed from the heating plate, closed and stored in the dark overnight. Next day, the $n$-heptane was filtered by a Büchner funnel (Qualitative Filter Paper 410, VWR International, slow filtration speed, particle retention value: $2-3 \mu \mathrm{m}$ ). The liquid phase was stored in another Erlenmeyer flask, which was sealed to avoid oxidation. The solid phase was washed twice with $100 \mathrm{~mL} n$-heptane at room temperature. Then, the solid phase was enclosed in a filter and put into a Soxhlet extractor with $750 \mathrm{~mL} n$-heptane as the solvent. To ascertain a high purity of asphaltenes, the extraction was continued for $48 \mathrm{~h}$ and the reflow from the extractor tested by putting one drop of the liquid on a glass plate. If there was no stain on the glass plate after evaporation of the solvent, the extraction was stopped; else the extraction was continued for another $24 \mathrm{~h}$. The two $n$-heptane insoluble phases were merged and enveloped in filter paper and subjected to toluene extraction with $750 \mathrm{~mL}$ toluene in a Soxhlet extractor. Duration and abortion criteria were the same as for the $n$-heptane extraction. The toluene was then evaporated and the solid phase was analyzed by gravimetry, FT-IR, and fluorescence spectroscopy. The filter-paper was also weighed to examine toluene-insoluble content, which was well below $0.05 \mathrm{wt} \%$ for all studied samples. Likewise, the liquid phase was filtered and the two $n$-heptane phases were merged and concentrated to a volume of about $50 \mathrm{~mL}( \pm 5 \mathrm{~mL})$.

This volume was then transferred onto a chromatographic column filled with $450 \mathrm{~g}$ of dry aluminum oxide to a column length of $80 \mathrm{~cm}( \pm 1 \mathrm{~cm})$ and prewetted with $400 \mathrm{~mL}$ of $n$-heptane. The solvent schedule was chosen according to ASTM 4124. However, due to the prewetting of the column, forerunnings of $350 \mathrm{~mL}$ were collected. The eluate 


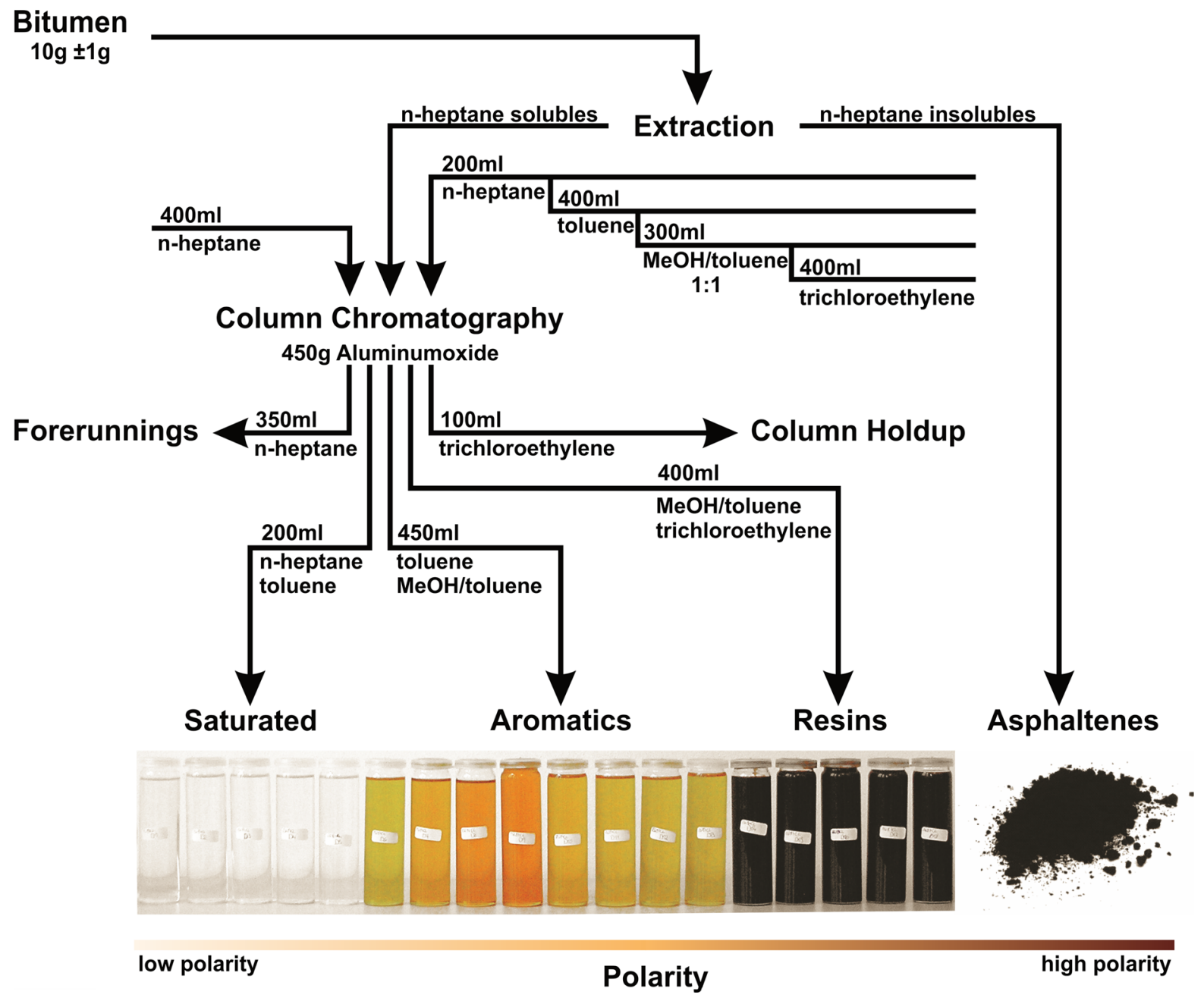

Fig. 1 Scheme of bitumen separation in a modified ASTM 4124 [4] procedure. Eluate allocations are approximations

was collected in $50 \mathrm{~mL}( \pm 2 \mathrm{~mL})$ glass beakers, sealed airtight and kept at $-15{ }^{\circ} \mathrm{C}$ in a fridge to slow degradation and oxidation processes. The solvent was removed by evaporation according to EN 1297-3 [23] and the fractions were analyzed as the solid phase.

\subsection{CLSM}

An inverted confocal fluorescence microscope ECLIPSE TE2000 (Nikon Corporation, Tokyo, Japan) was used in this study. The microscopic setup offers both a transmission and a CLSM array. For the transmission mode, a T-DH 100 W Illumination Pillar (Koehler Type) is employed. An Argon-ion laser is used as source of excitation radiation for the fluorescence scanning mode. Samples were studied using an excitation wavelength of $488 \mathrm{~nm}$, the most intense frequency of emission provided by the Argonion laser, and emission sided, a band pass filter 515/30 was employed, setting the window of observation to $500-530 \mathrm{~nm}$ of fluorescent emission. The standard software Nikkon EZ-C1 was used to control and operate the TE2000 setup. Image post-processing for optimal contrast and conversion to black and white was performed with Corel PaintShop Photo X3 version 13.2.1.32.

For sample preparation, the bitumen was heated to about $150-200{ }^{\circ} \mathrm{C}$ as necessary for melting the sample. A small drop of bitumen was placed on an ultrathin glass slide. Subsequently, another glass slide 
was placed onto the bitumen drop. An additional heating period of $15 \mathrm{~min}$ at $150{ }^{\circ} \mathrm{C}$ for the samples was implemented, allowing the bitumen film to spread and become very thin. These thin films were then examined by CLSM. The mineral aggregates/bitumen mixtures were prepared in a similar fashion. A small drop of bitumen was allowed to spread on an ultrathin glass slide and then the mineral aggregates were added on top. Then the second glass slide was put onto the mixture. In order to introduce shear forces into the material, the still hot glass slides were slid against each other. Then the sample was prepared following the same procedure employed on the pure bitumen samples.

\subsection{Fluorescence spectroscopy}

For fluorescence spectroscopy, an Edinburgh Instruments FSP920 photoluminescence spectroscopy setup was employed. The setup is equipped with a XE900 Xenon Arc Lamp, which provides high intensity radiation on a broad spectrum. The setup employs double Czerny-Turner monochromators (type TMS300) at both excitation and emission arms, guaranteeing a very narrow spectral bandwidth selection. The detector is a S900 single-photon photomultiplier (type R928). The spectrometer was used to conduct both excitation and emission measurements. For sample preparation, the bitumina were heated to $150{ }^{\circ} \mathrm{C}$ and a drop of bitumen was applied to a standard microscopic slide. This slide was stored at elevated temperature $\left(80^{\circ} \mathrm{C}\right)$ for 5 min to allow the drop to spread and increase its surface. Afterwards the samples were cooled to room temperature and subjected to fluorescence spectroscopy. To rule out any oxidative influence on the sample surface, one set of samples was prepared under a continuous $\mathrm{N}_{2}$ flow, limiting the oxygen uptake of the sample. For bitumen fractions, this treatment was not necessary, because the maltene phase and its components are viscous liquids at room temperature and can be applied directly at room temperature to the glass slide. The asphaltenes were taken up with toluene and then dripped slowly on the warm glass surface $\left(80^{\circ} \mathrm{C}\right)$ to allow the formation of a thin film. Two different modes of measurement were employed, excitation scans (variable excitation, fixed detection wavelength) and emission scans (fixed excitation, variable detection wavelength). For the excitation scans, the same detection wavelength as used at the microscope was chosen, $525 \mathrm{~nm}$, and a spectral range of 200-500 nm excitation wavelength was observed. It is important to insert a $340 \mathrm{~nm}$ cutoff filter emission sided to avoid second diffraction order radiation of the Rayleigh line at $207.5 \mathrm{~nm}$ on the detector. For the emission spectra, two wavelengths have been studied carefully. First an excitation wavelength of $488 \mathrm{~nm}$ was selected, because this is the most intense excitation wavelength available in the CLSM setup. For detection, a spectral range of $500-750 \mathrm{~nm}$ (detection limit) was chosen. To check for high energy fluorescence transitions, we employed a wavelength of $280 \mathrm{~nm}$ and a detection range of 300-540 nm without filter, and 480-750 nm with an emission sided $340 \mathrm{~nm}$ cutoff filter. The overlap was used to append the spectra. All spectra were measured with the following setup parameters: step width $1 \mathrm{~nm}$, scan slit set for $\Delta \lambda$ value of $\pm 1 \mathrm{~nm}$, dwell time $1 \mathrm{~s}$, with 5 repeats. Additionally, emission mappings of selected bitumen samples were performed for a range of $280-530 \mathrm{~nm}$ excitation. An emission window of 390-640 nm was observed corrected by an offset value of $20 \mathrm{~nm}$ to avoid the respective Rayleigh lines. Also, a $340 \mathrm{~nm}$ cutoff filter was employed. The mappings were performed over $18 \mathrm{~h}$. The software used to record the spectra was the Edinburgh Instruments F900 Version 6.87 (Build 1). The spectra were processed employing OriginPro 8.6.0G by OriginLab Corporation.

\section{Results}

\subsection{CLSM}

\subsubsection{Bitumen samples}

CLSM revealed typical structural phenomena, which were observed for all pure bitumina. Fluorescent centers of roughly ellipsoid shape, varying in size and distribution were visualized. Their spatial distribution is disordered and no anisotropies can be detected (Fig. 2). Exemplary, three images are shown in Fig. 2. A strong connection to the mechanical and rheological properties can be reasonably assumed as predicted by multi-scale models [24, 42, 43]. The size and distribution of fluorescence emissions in bitumen seems to be directly linked to the mechanical properties, as the vacuum cracking and flashing processes seem to 



Fig. 2 CLSM images of 70/100A, PE1005, 70/100B employing $488 \mathrm{~nm}$ excitation wavelength and an observation window $500-530 \mathrm{~nm}$ showing fluorescent centers as bright structures of roughly ellipsoid shape

reduce frequency of occurrence and contrast of fluorescent emissions (see Fig. 2), which results in the hardening of bitumen from the very soft PE1005 to 70/100 penetration category.

\subsubsection{Bitumen and mineral aggregate mixtures}

The measurement of mixtures of bitumen and filler was at the center of our interest. The latter, is essentially finely powdered mineral aggregate. We have assumed an interaction between the most polar molecules of bitumen, which are asphaltenes and resins, with the polar surface of mineral aggregates.

As a preliminary experiment, the fluorescent capabilities of the mineral aggregates were determined. It was confirmed that the fluorescence signal of the studied fillers is weaker than that of the fluorescent centers in bitumen by several orders of magnitude. First experiments have indicated high concentrations of fluorescent material in the direct vicinity of the mineral aggregates, forming morphologies, which appear as shining "halos". This phenomenon stems from fluorescent molecules accumulated at the surface of the mineral component, although it is not certain whether this accumulation is promoted by the preparation process. Since this effect could be observed using mixtures of different bitumina and fillers, it was strongly suggested that these "halos" were caused by actual physico-chemical interaction of the filler and the fluorescent molecules. An additional resting period of $20 \mathrm{~min}$ at $170{ }^{\circ} \mathrm{C}$ was included after the sample preparation process, to allow any reforming or migration processes to take place. This allowed exclusion of mechanical strain as a reason for the formation of the "halos". After this resting period, the "halos" vanished and the samples exhibit a typical bitumen microstructure. The assumption that the implantation of the mineral aggregates into the bitumen is the reason for the formation of these "halos" (see arrow in Fig. 3, middle) is strongly supported by these pictures. The extended resting period on the heated plate allows the bitumen structure to relax and the fluorescent particles return to a statistical and disordered distribution.

\subsection{Fluorescence spectroscopy}

The identity of the fluorescent centers can only be assessed by looking at the fluorescent capabilities of the bitumen fractions. In comparison to the CLSM images, fluorescence spectroscopy yields an integrated spectrum that is not capable of visualizing spatial distributions or point-by-point scanning. However, through separation of bitumen into fractions according to solubility and polarity, the spectral information can provide additional structural information by inference. A closer look on the basic physicochemical properties of bitumen reveals that bitumen contains only three fractions that could theoretically be the origin of the fluorescent signal: a) The asphaltenes, b) the resins, and c) the aromatics are, based on their general chemical description and nature, capable of fluorescence. Saturates can easily be dismissed as a source of fluorescent emission, due to the well-defined chemical nature of the fraction and the lack of conjugated $\pi$-electron systems. 

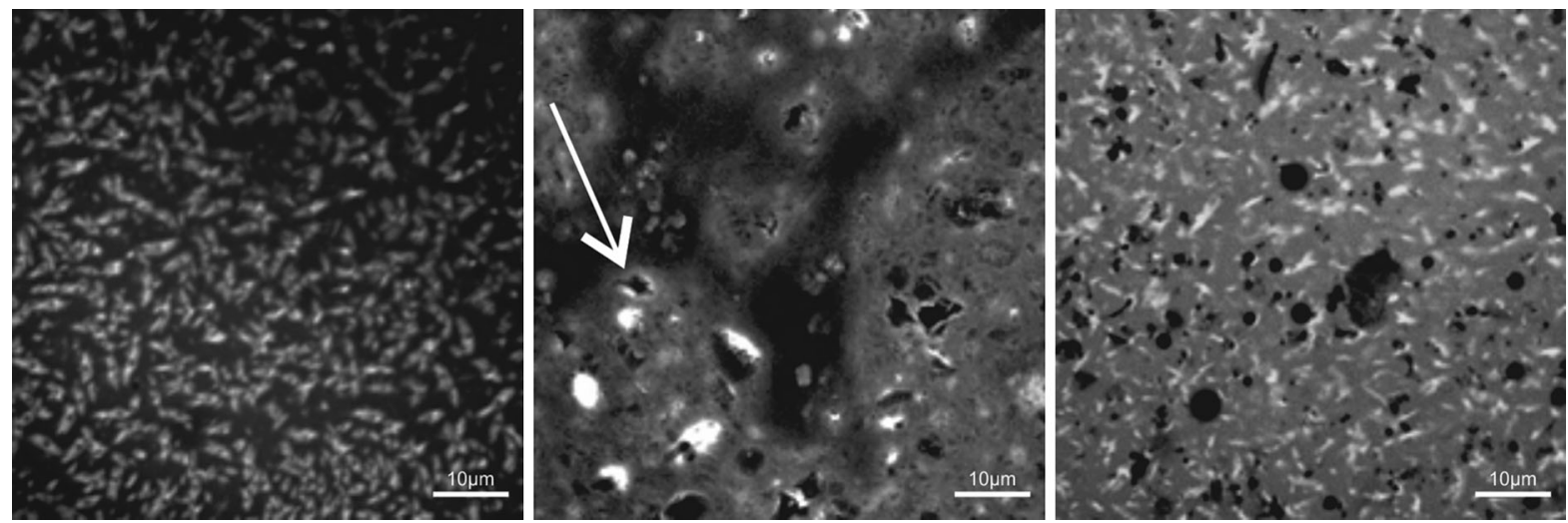

Fig. 3 CLSM image of PE1005 (left), mixture of PE1005 with filler (middle) showing the "halo" effect (arrow), mixture of PE1005 with filler after storage at $170{ }^{\circ} \mathrm{C}$ for $20 \mathrm{~min}$ (right)
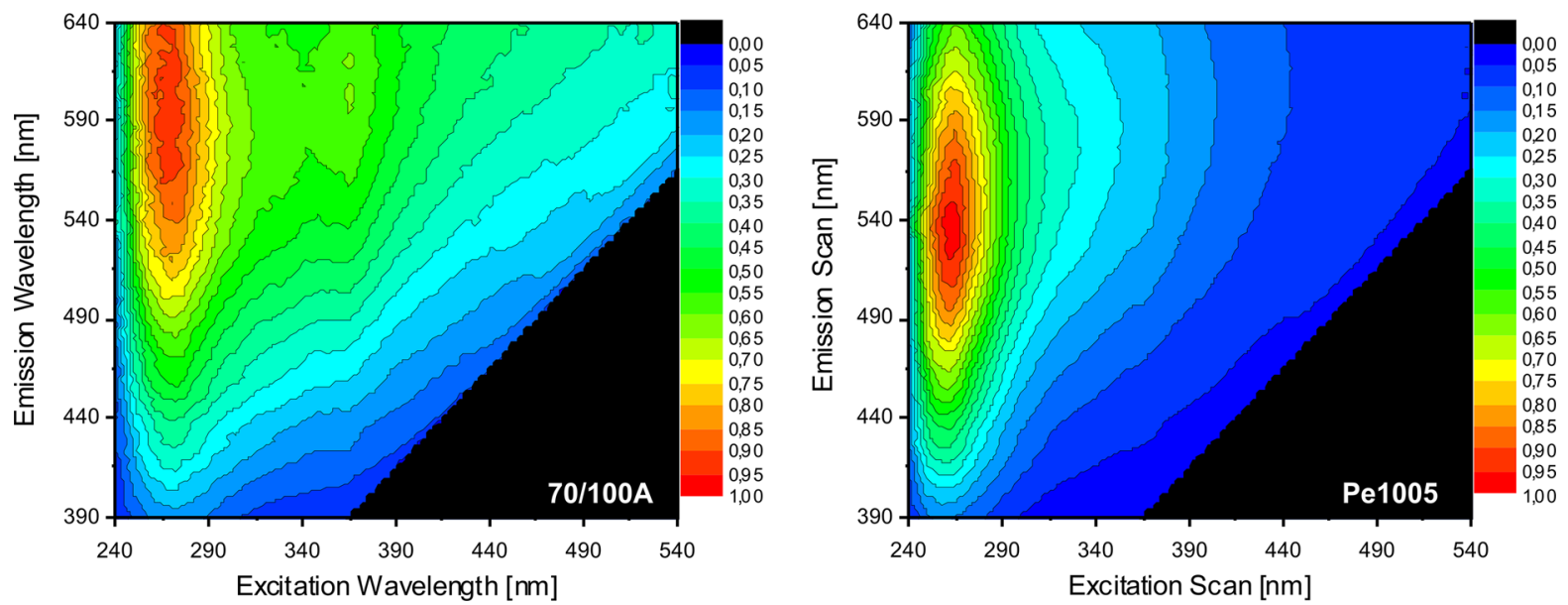

Fig. 4 Normalized fluorescence mappings of 70/100A (left) and PE1005 (right): bitumen precursor PE1005 is significantly different. (Color figure online)

\subsubsection{Fluorescence mapping of bitumen}

The fluorescence mappings of bitumen reveal strong similarities in the structure. The spectra for the normal bitumen are all very similar and exemplary, the spectrum for $70 / 100 \mathrm{~A}$ is shown as a typical bitumen spectrum (see Fig. 4) in comparison to PE1005. The samples exhibit a maximum of emission (Fig. 4, red area) at about $240-270 \mathrm{~nm}$ excitation wavelength. This area is slightly different for bitumina, but significantly different for the bitumen precursor. The fluorescence signal strength declines towards higher wavelengths of emission. Additionally, at around $360 \mathrm{~nm}$ excitation wavelength a second maximum was detected (light green) for all bitumen samples. Only for PE1005 (Fig. 4, right) a bitumen precursor, this area is not visible. The similarities in the spectra indicate that there is a typical composition of the studied bitumen samples in terms of aromatic components and their substituents, since chemical substituents gravely influence the absorptive and fluorescent properties of conjugated $\pi$ electron systems. Additionally, the existence of at least two main classes of fluorescence capable molecules can be deduced by the two maxima in the spectra. Differences in the predominant chemical structure of these two classes are difficult to assess. Actually, the surrounding chemical vicinity, could strongly influence the fluorescent emissions of the respective species and cause shifts of 100-200 nm in the spectrum depending on its polarity and aromaticity $[25,56]$.

The Kasha-Vavilov rule states that the quantum yield of fluorescence transitions is independent of the 




Fig. 5 Emission and excitation spectra of Bitumen 70/100A (black) in comparison with maltenes (blue) and asphaltenes (light grey). Asphaltenes show barely any fluorescence.

excitation wavelength, if the provided energy causes the transition into an excited state but does not cause ionization. Although exceptions from this rule exist, generally the rule applies to most aromatic molecules [58]. However, bitumen is not a pure, aromatic substance but rather a colorful mix of various compounds. Although bitumen generally seems to follow this rule, there is an anomaly at wavelengths below $260 \mathrm{~nm}$ wavelength of excitation radiation. Generally, fluorescent emission in this spectral region is rare, because the corresponding energy is sufficient to cause dissociation or predissociation in many molecules and the great variety of compounds in bitumen makes the existence of such bonds a certainty [49].

\subsubsection{Emission and excitation scans of bitumen and SARA-fractions}

The mapping mode for fluorescence spectroscopy is very limited in terms of signal intensity and spectral resolution, because of the number of spectra and the resulting measurement time. The long measurement times could induce changes in the sample surface of the irradiated area, which is due to the high illumination intensity. Especially for high energy radiation close to the UV range, this might have an important impact, which has been controlled for by performing emission and excitation scans at the exact wavelengths employed in the CLSM setup.

The comparison between pure bitumen, asphaltenes, and maltenes (Fig. 5) reveals that the fluorescent capabilities of asphaltenes are rather limited in the

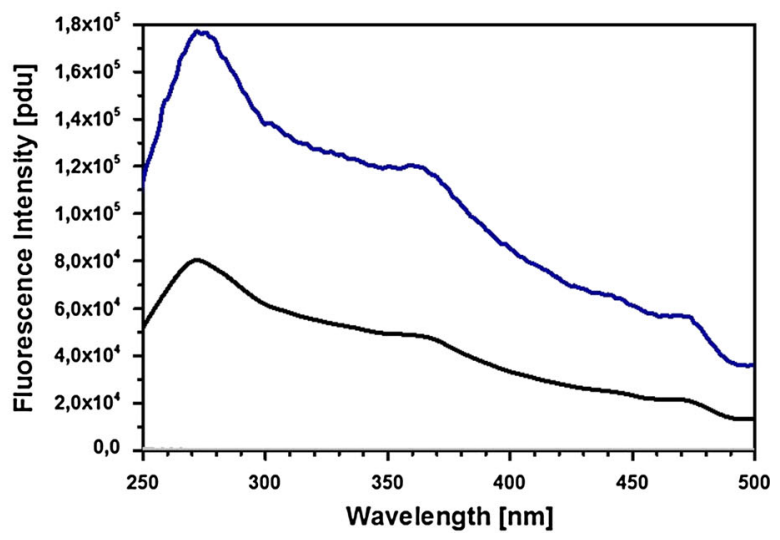

Emission spectra employed $488 \mathrm{~nm}$ excitation wavelength, excitation spectra were measured at $525 \mathrm{~nm}$ detection. (Color figure online)

visible spectral range. Pure bitumen and maltenes exhibit very similar fluorescent behavior, although the maltenes signal strength is greater by one order of magnitude. Employing $488 \mathrm{~nm}$ excitation radiation (Fig. 5, left), the fluorescence intensity increases steeply from 500 to $535 \mathrm{~nm}$ and remains almost constant, with a weakly expressed minimum at $555 \mathrm{~nm}$, to the second maximum at $580 \mathrm{~nm}$. From that point on, fluorescent capabilities show a smooth decline for rising wavelengths of detection. In comparison, asphaltenes show almost no fluorescent capabilities in the spectral window, which can be observed with the present setup. However, they might exhibit fluorescent capabilities in the near infrared region. Fluorescence transitions of low energy consequently point to larger conjugated systems and/or a rising amount of bathochromic functional groups. Also, very polar chemical vicinity can cause shifts in fluorescent spectra. The location of maxima and shoulders remains unchanged for the separated maltenes. Additionally, the presence of asphaltenes seems to quench the fluorescence of the maltene phase. For $525 \mathrm{~nm}$ detection and varying excitation wavelength (Fig. 5, right), the same changes in fluorescent intensity can be observed. The asphaltenes show little to no fluorescent capabilities at the given conditions. The maxima/shoulders are located at 210, 270-280, 370, and $480-490 \mathrm{~nm}$ and are, consistently with the emission scan discussed beforehand, exactly at the same wavelength for bitumen and the maltenes. The shoulder at $480-490 \mathrm{~nm}$ is consistent with the excitation wavelength employed in the CLSM setup. 
A quenching effect can either be direct by changing the chemical vicinity of the aromatics, or indirect, if the addition of the asphaltenes induces structural changes in the bitumen, which can have an even greater impact on the chemical environment for a chemically similar group of molecules. The formation of aggregated structures of asphaltenes in bitumen is undisputed. These spectra point to a direct structural impact by the asphaltenes on the material, but are not sufficient to identify the fluorescent phase in bitumen.

If the maltenes are broken down into the classical SARA fractions by column chromatography over alumina (cp. Sect. 2.2), the fluorescence capabilities of the pure fractions can be determined. Exemplary, the highest weight fraction of the respective SARA fraction were chosen (cp. Fig. 6): Saturates 3, Aromatics 2, Resins 2, and Asphaltenes, since the spectra are very similar for the fractions of all samples tested. For the saturated and the asphaltene fraction little to no fluorescent emissions could be found (Fig. 7). However, the aromatic fraction exhibits the highest fluorescence activity in the 450-500 $\mathrm{nm}$ window of the band-pass filter employed for wavelength selection in the CLSM setup. If compared to the resins, the intensity is greater by a factor of 200 , which is a significant difference. The fluorescent centers visible in CLSM can be identified as to be composed primarily of aromatics and to a far lesser extent by resins. Furthermore, the background fluorescence of the sample indicates that there is a distribution of the fluorescent fractions into the other phases.

\section{Discussion}

We have shown that the fluorescent centers that can be visualized by CLSM are not caused originally by asphaltenes, as was assumed before [5]. First fractioning experiments found that the asphaltenes are hardly capable of fluorescence at $488 \mathrm{~nm}$ excitation and the 500-530 nm detection window, on the other hand, maltenes produce very strong fluorescence signals. When fractioning the maltene phase, aromatics and resins are the only constituents that show significant capability of fluorescence. Without further considerations, the basic conclusion is that there exists
Fig. 6 Gravimetric analysis of bitumen fractions by fraction taken and by SARA scheme for exemplary separation

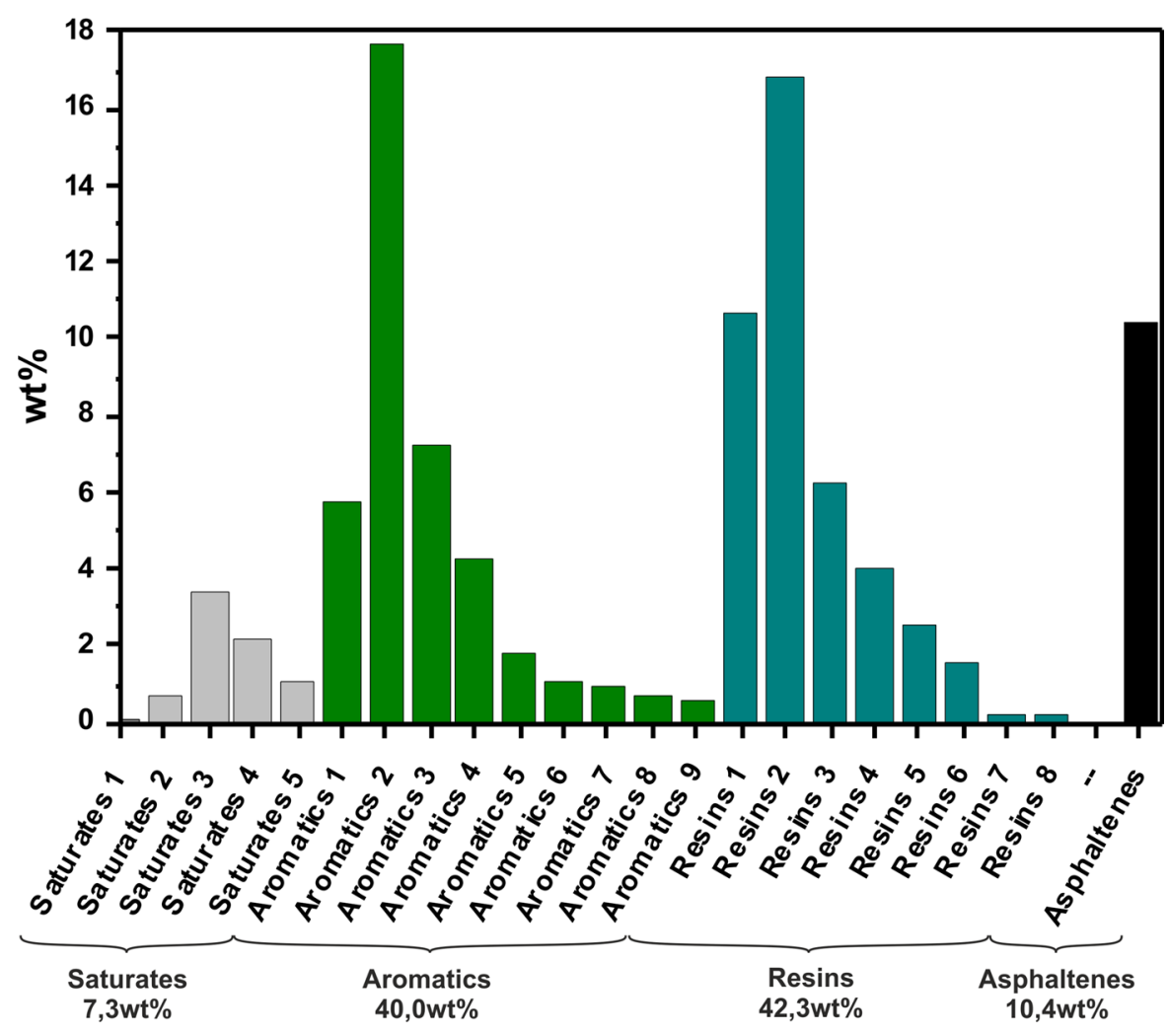





Fig. 7 Excitation spectra at $525 \mathrm{~nm}$ emission wavelength for aromatics (green, left), resins (turquois, right), asphaltenes (black, right), and saturates (grey, right) of bitumen 70/100B. (Color figure online)

a spatial non-continual distribution of volume elements in bitumen, which exhibit a significantly higher concentration of fluorescence capable molecules of the aromatics fraction. In other words, the existence of structures consisting mainly of aromatics and to a lesser extent of resins was proven beyond doubt.

If the similar size of the structures is taken into account, the fluorescent centers can reasonably be assumed to form the so called "peri-phase" often shown by AFM imaging [36, 51, 53] to surround the "bee-like" catana phase. As there is a sharp phasecontrast between the three phases, the name microcapsule is probably more correct then micelle due to the size of the structures (IUPAC definitions).

The question, whether the inside of the microcapsules is an agglomeration of asphaltenes or waxcrystallization, cannot be answered by CLSM. The wax-theory is mainly based on the observation that the frequency of occurrence of these structures rises with increasing content of wax and saturates respectively $[33,36]$. Also, undisputable observations of microstructural phenomena in pure maltenes [53] were made. Additionally, by using heating and cooling cycles, it was proven that these structures vanish completely at around $90{ }^{\circ} \mathrm{C}$ and reemerge when the sample is cooled down [39], similar to a classical crystallization scenario. This is interpreted as being in the same temperature range as the melting points of waxes commonly found in bitumina [39].

The asphaltene agglomeration theory is mainly based on the observation of asphaltene precipitation in various solvents and also crude oil [3]. The capability for self-assembly of polyaromatic structures is an often observed phenomenon. Several studies found self-ordering behavior for such molecules and it has been proven that this effect, which is caused by $\pi-\pi$ interactions, can also be found in asphaltenes [2, 12, $13,19,20,55,59,62]$. For most bitumina studied in literature, the natural wax fraction is below $2 \mathrm{wt} \%$ as measured by standard distillation methods [32], while the typical asphaltene content is around $10 \mathrm{wt} \%$.

Detailed studies of waxes in bitumen have shown that these are largely dominated by $n$-alkanes and isoalkanes with carbon numbers of C15-C57 [32], and melting points of around $40-65^{\circ} \mathrm{C}$. Furthermore, a recently concluded round-robin test focused the glass transition temperature reliability via DSC testing and found that the addition of $3 \mathrm{wt} \%$ wax had no significant influence on the glass transition temperature $\left(T_{\mathrm{g}}\right)$ of bitumen [51], limiting the calculation of wax content by DSC. The same study found that the melting temperature of the natural waxes in bitumen is around $25{ }^{\circ} \mathrm{C}$. These findings make it rather difficult to correlate the vanishing of the structures at $90{ }^{\circ} \mathrm{C}$ with the melting point of waxes. Additionally, AFM was successfully employed to visualize these structures for bitumen with very low saturates contents (3.8\%) [15]. The polarity and hence the solubility parameters of a solvent system may change to a great extent, if apolar material is added. This can cause aggregation and phase separation processes of polar constituents that were soluble in the original material. It is thus also possible to interpret this effect as the formation of further aggregates of polar material in an increasingly 
Fig. 8 Qualitative scheme: distribution of the SARA fractions in bitumen (left), schematic of asphaltene micelle and mantle and listing of main fractions by frequency of occurrence

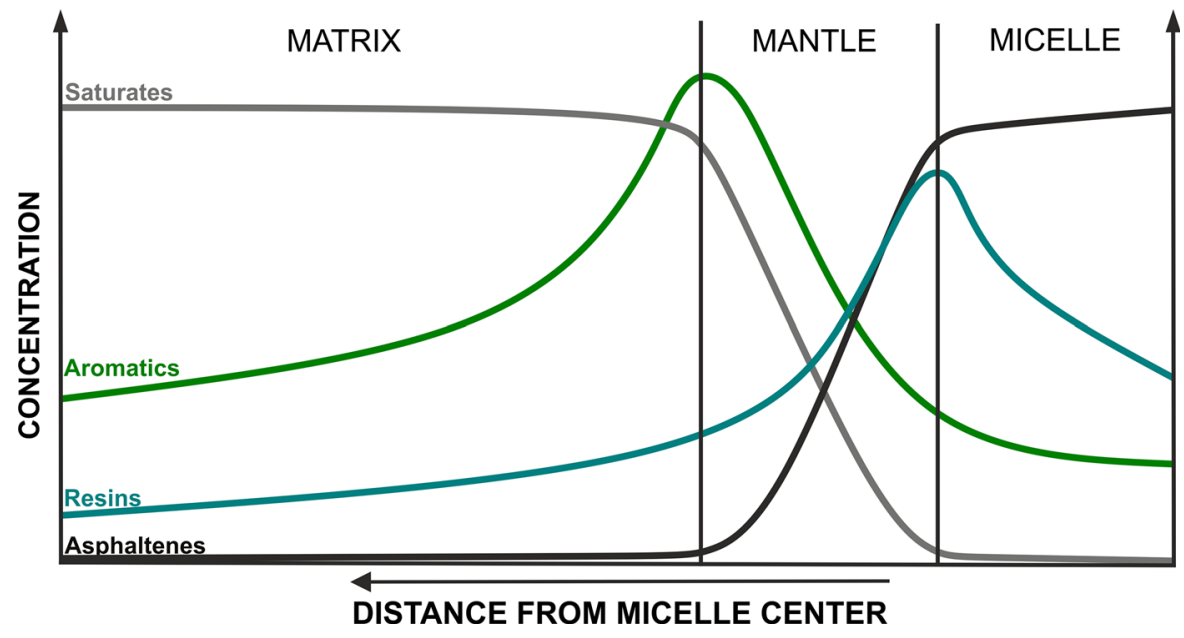

apolar matrix. From a micromechanical point of view, the addition of around $5 \%$ of asphaltenes has a tremendously high impact on the rheological and mechanical behavior of maltenes, indicating a huge impact on the microstructure by the addition of the asphaltenes [11].

Although a co-precipitation of certain waxes with the asphaltenes cannot be dismissed entirely, these facts strongly favor the asphaltene agglomeration model, when dealing with non-modified, low wax bitumina. Combining the model approaches with our measurements, we conclude the existence of three phases, the matrix dominated by saturates, the asphaltene dominated agglomerate phase, and the mantle phase, which mainly consists of aromatics and to a lesser extent of resins. The first two phases are not directly soluble in each other, but aromatics and resins exhibit varying solubility in both and serve as a stabilizer (Fig. 8, right). The polar and aromatic nature of the resins allows them to form a mantle around the micelle bridging the polarity gap between the very polar asphaltenes and the less polar matrix. Figure 8 doesn't represent actual measured values, but rather shows a possible distribution of the SARA fractions, as a model approach.

The addition of mineral aggregates to bitumen has little to no impact on the bitumen microstructure as visualized by CLSM. This indicates a lack of physicochemical interaction between the two phases, which in turn could indicate no chemical and only little physical interaction between the mantle phase and the minerals. Investigations of this interaction have shown that it is mostly based on dispersive interaction [34]. This suits our model of an apolar matrix quite well. If the asphaltenes as the most polar molecules in bitumen were to interact with the minerals, the aromatic shell would have to be located on the outside of the mineral particle (intermediate halo observation, see Fig. 3, middle). However, this transition state vanishes after a short relaxation time.

\section{Conclusion}

CLSM has been used as a highly effective imaging technique on bitumen. The technique allows the confirmation of the asphaltene agglomeration theory in the form of a core-shell particle like arrangement. For the SBS modified bitumen, the microstructure is perfectly visible. The fluorescent phase was also shown to play no detectable role in the interaction between bitumen and mineral aggregates. This indicates a general lack of interaction on a structural level. In total, this limits the interaction to the molecules in the matrix, indicating that adhesion between minerals and bitumen is mostly based on mechanical phenomenon and perhaps to a lesser extent on van der Waals forces [34].

CLSM pictures similar to ours have been interpreted by many researchers as asphaltene micelles, attributing the fluorescent signals to asphaltenes themselves. Our results of the fractionation experiments, however, indicate that in fact the capability of the asphaltenes for fluorescence at $488 \mathrm{~nm}$ excitation is insignificant. Likewise, the emission signal strength at $525 \mathrm{~nm}$ detection wavelength is very low. Furthermore, 
fractionation according to ASTM 4124 and subsequent fluorescence analysis showed clearly that the aromatics fraction is the source of the fluorescent emissions. When combining this structural information with the micelle theory, the fluorescent signals still originate from these asphaltene micelles. However, it has to be pointed out that the signals originate from the stabilizing mantle of declining polarity around the asphaltene agglomerates and not from the inner core of the asphaltenes themselves.

These results have been successfully employed in further investigations regarding microstructure and microstructural changes at the ageing of bitumen [11]. The mantle surrounding the asphaltene agglomerate seems to be the critical part. Overall, these effects play a critical role that has been underrated in former studies of bitumen and asphalt ageing. CLSM and fluorescence spectroscopy can be regarded as solid methods for such investigations.

Acknowledgments We express our gratitude towards our governmental funding partners, the Austrian Research Promotion Agency (FFG) in the project "OEKOPHALT - Chemical and physical fundamentals of bitumen ageing for ecological asphalt recycling". Furthermore, we thank our cooperation and funding partners from asphalt industry, namely: Pittel+Brausewetter GmbH, Swietelsky Baugesellschaft m.b.H., Nievelt Labor $\mathrm{GmbH}$, and the OMV AG for their continued support.

\section{References}

1. Abraham H (1920) Asphalts and allied substances, 4th edn. D. Van Nostrand Company Inc., New York

2. Acevedo S, García LA, Rodríguez P (2012) Changes of diameter distribution with temperature measured for asphaltenes and their fractions A1 and A2. Impact of these measurements in colloidal and solubility issues of asphaltenes. Energy Fuels 26:1814-1819. doi:10.1021/ef201947h

3. Aske N, Kallevik H, Johnsen EE, Sjöblom J (2002) Asphaltene aggregation from crude oils and model systems studied by high-pressure NIR spectroscopy. Fuel 2002:1287-1296

4. ASTM International (2001) Standard test methods for separation of asphalt into four fractions, vol D4124-01. ASTM International, West Conshohocken

5. Bearsley S, Forbes A, Haverkamp RG (2004) Direct observation of the apshaltene structure in paving-grade bitumen using confocal laser-scanning microscopy. J Microsc 215:149-155

6. Bhasin A (2006) Development of methods to quantify bitumen-aggregate adhesion and loss of adhesion due to water. PhD Thesis, Texas A\&M University

7. Boulangé L, Bonin E, Saubot M (2013) Physicochemical characterisations of the bitumen-aggregate interface to get a better understanding of stripping phenomena. Road Mater
Pavement Des 14:384-403. doi:10.1080/14680629.2013. 803494

8. Champion-Lapalu L, Wilson A, Fuchs G, Martin D, Planche JP (2002) Cryo-scanning electron microscopy: a new tool for interpretation of fracture studies in bitumen/polymer blends. Energy Fuels 16:143-147. doi:10.1021/ef010122s

9. Corbett LW (1969) Composition of asphalt based on generic fractionation. using solvent deasphaltening, elutionadsorption chromatography, and densimetric characterization. Anal Chem 41:576-579

10. DIN Deutsches Institut für Normung, e.V. (2012) Bitumen und bitumenhaltige Bindemittel-Terminologie, vol EN 12597:2012, Berlin

11. Eberhardsteiner L, Füssl J, Hofko B, Handle F, Hospodka M, Blab R, Grothe H (2014) Influence of asphaltene content on mechanical bitumen behavior-experimental investigation and micromechanical modeling. Mater Struct. doi:10. 1617/s11527-014-0383-7

12. Eyssautier J, Espinat D, Gummel J, Levitz P, Becerra M, Shaw J, Barré L (2012) Mesoscale organization in a physically separated vacuum residue: comparison to asphaltenes in a simple solvent. Energy Fuels 26:2680-2687. doi:10. 1021/ef201411r

13. Eyssautier J, Hénaut I, Levitz P, Espinat D, Barré L (2012) Organization of asphaltenes in a vacuum residue: a smallangle X-ray scattering (SAXS)-viscosity approach at high temperatures. Energy Fuels 26:2696-2704. doi:10.1021/ ef $201412 j$

14. Fawcett A, McNally T (2003) Polystyrene and asphaltene micelles within blends with a bitumen of an SBS block copolymer and styrene and butadiene homopolymers. Colloid Polym Sci 281:203-213. doi:10.1007/s00396-0020762-4

15. Fischer HR, Dillingh EC (2014) On the investigation of the bulk microstructure of bitumen-introducing two new techniques. Fuel 118:365-368. doi:10.1016/j.fuel.2013.11.008

16. Fletcher KA et al (2006) Molecular fluorescence, phosphorescence, and chemiluminescence spectrometry. Anal Chem 78:4048-4068

17. Forbes RJ (1936) Bitumen and petroleum in antiquity. E.J. Brill, Leiden

18. Forbes A, Haverkamp RG, Robertson T, Bryant J, Bearsley $S$ (2001) Studies of the microstructure of polymer-modified bitumen emulsion using confocal laser scanning microscopy. J Microsc 204:252-257

19. Goual L, Sedghi M, Wang X, Zhu Z (2014) Asphaltene aggregation and impact of alkylphenols. Langmuir 30:5394-5403. doi:10.1021/la500615k

20. Haji-Akbari N, Masirisuk P, Hoepfner MP, Fogler HS (2013) A unified model for aggregation of asphaltenes. Energy Fuels 27:2497-2505. doi:10.1021/ef4001665

21. Handle F, Grothe H, Neudl S (2012) Confocal laser scanning microscopy-observation of the microstructure of bitumen and asphalt concrete. Paper presented at the 5th Eurasphalt \& Eurobitume Congress, Istanbul, 13-15 June 2012

22. Hefer A, Little D (2005) Adhesion in bitumen-aggregate systems and quantification of the effects of water on the adhesive bond. $\mathrm{PhD}$ thesis, Texas A\&M University

23. IN Deutsches Institut für Normung, e.V. (2013) AsphaltPrüfverfahren für Heißasphalt, vol EN 12697-3:2013, Berlin 
24. Lackner R, Spiegl M, Blab R, Eberhardsteiner J (2005) Is low-temperature creep of asphalt mastic independent of filler shape and mineralogy? Arguments from multiscale analysis. J Mater Civ Eng 17:485-491

25. Lambert JB, Gronert S, Shurvell HF, Lightner DA (2012) Spektroskopie - Strukturaufklärung in der organischen Chemie, 2nd edn. Pearson Deutschland GmbH, Munich

26. Le Guern M, Chailleux E, Farcas F, Dreessen S, Mabille I (2010) Physico-chemical analysis of five hard bitumens: identification of chemical species and molecular organization before and after artificial aging. Fuel 89:3330-3339. doi:10.1016/j.fuel.2010.04.035

27. Lesueur D (2009) The colloidal structure of bitumen: consequences on the rheology and on the mechanisms of bitumen modification. Adv Colloid Interface Sci 145:42-82. doi:10.1016/j.cis.2008.08.011

28. Loeber L, Sutton O, Morel J, Valleton J-M, Muller G (1996) New direct observations of asphalts and asphalt binders by scanning electron microscopy and atomic force microscopy. J Microsc 182:32-39

29. Loeber L, Muller G, Morel J, Sutton O (1998) Bitumen in colloid science: a chemical, structural and rheological approach. Fuel 77:1443-1450

30. Loeber L, Alexandre S, Muller G, Triquineaux J-C, Jolivet Y, Malot M (2000) Bituminous emulsions and their characterization by atomic force microscopy. J Microsc 198:10-16

31. Louw K, Rossmann D, Cupido D (2004) The vialit adhesion test: is it an appropriate test to predict low temperature binder/aggregate failure? In: Proceedings of the 8th conference on asphalt pavements for southern Africa, 7

32. Lu X, Redelius P (2006) Compositional and structural characterization of waxes isolated from bitumens. Energy Fuels 20:653-660. doi:10.1021/ef0503414

33. Lu X, Langton M, Olofsson P, Redelius P (2005) Wax morphology in bitumen. J Mater Sci 40:1893-1900

34. Lyne ÅL, Birgisson B, Redelius P (2011) Interaction forces between mineral aggregates and bitumen calculated using the Hamaker constant road. Mater Pavement Des. doi:10. 1080/14680629.2010.9690336

35. Lyne ÅL, Wallqvist V, Birgisson B (2013) Adhesive surface characteristics of bitumen binders investigated by atomic force microscopy. Fuel 113:248-256. doi:10.1016/j. fuel.2013.05.042

36. Lyne ÅL, Wallqvist V, Rutland MW, Claesson P, Birgisson B (2013) Surface wrinkling: the phenomenon causing bees in bitumen. J Mater Sci. doi:10.1007/s10853-013-7505-4

37. Merino-Garcia D, Shaw J, Carrier H, Yarranton H, Goual L (2010) Petrophase 2009 panel discussion on standardization of petroleum fractions. Energy Fuels 24:2175-2177. doi:10. 1021/ef9009263

38. Mikula RJ, Munoz VA (2000) Characterization of emulsions and suspensions in the petroleum industry using cryoSEM and CLSM. Colloids Surf A 174:23-36

39. Nahar SN, Schmets AJM, Scarpas A, Schitter G (2013) Temperature and thermal history dependence of the microstructure in bituminous materials. Eur Polym J 49:1964-1974. doi:10.1016/j.eurpolymj.2013.03.027

40. Ortega-Rodriguez A, Cruz SA, Gil-Villegas A, GuevaraRodriguez F, Lira-Galeana C (2003) Molecular view of the asphaltene aggregation behavior in asphaltene-resin mixtures. Energy Fuels 17:1100-1108

41. Petersen JC (2009) A review of the fundamentals of asphalt oxidation. Transp Res Circ E-C140:1-78

42. Pichler C, Lackner R (2009) Upscaling of viscoelastic properties of highly-filled composites: investigation of matrix-inclusion-type morphologies with power-law viscoelastic material response. Compos Sci Technol 69:2410-2420. doi:10.1016/j.compscitech.2009.06.008

43. Pichler C, Lackner R, Aigner E (2012) Generalized selfconsistent scheme for upscaling of viscoelastic properties of highly-filled matrix-inclusion composites-application in the context of multiscale modeling of bituminous mixtures. Composites B 43:457-464. doi:10.1016/j.compositesb. 2011.05.034

44. Pollack SS, Yen TF (1970) Structural studies of asphaltics by X-ray small angle scattering. Anal Chem 42:623-629

45. Read J, Whiteoak D (2003) The shell bitumen handbook, 5 th edn. Thomas Telford Ltd., London

46. Redelius P, Soenen H (2015) Relation between bitumen chemistry and performance. Fuel 140:34-43. doi:10.1016/j. fuel.2014.09.044

47. Sengoz B, Isikyakar G (2008) Analysis of styrene-butadiene-styrene polymer modified bitumen using fluorescent microscopy and conventional test methods. J Hazard Mater 150:424-432. doi:10.1016/j.jhazmat.2007.04.122

48. Sheu EY (1996) Physics of asphaltene micelles and microemulsions - theory and experiment. J Phys: Condens Matter 8:A125-A141

49. Skoog DA, Leary JJ (1996) Instrumentelle Analytik: Grundlagen - Geräte - Anwendungen, 2nd edn. Springer, Berlin

50. Slomkowski S et al (2011) Terminology of polymers and polymerization processes in dispersed systems (IUPAC Recommendations 2011). Pure Appl Chem 83:2229-2259. doi:10.1351/pac-rec-10-06-03

51. Soenen $\mathrm{H}$ et al (2013) Laboratory investigation of bitumen based on round robin DSC and AFM tests. Mater Struct. doi:10.1617/s11527-013-0123-4

52. Solaimany Nazar AR, Rahimi H (2009) Investigation on agglomeration-fragmentation processes in colloidal asphaltene suspensions. Energy Fuels 23:967-974. doi:10. 1021/ef800728h

53. Sourty ED, Tamminga AY, Michels MA, Vellinga WP, Meijer HE (2011) The microstructure of petroleum vacuum residue films for bituminous concrete: a microscopy approach. J Microsc 241:132-146. doi:10.1111/j.13652818.2010.03409.x

54. Topal A (2010) Evaluation of the properties and microstructure of plastomeric polymer modified bitumens. Fuel Process Technol 91:45-51. doi:10.1016/j.fuproc.2009.08.007

55. Trejo F, Ancheyta J, Rana S (2009) Structural characterization of asphaltenes obtained from hydroprocessed crude oils by SEM and TEM. Energy Fuels 23:429-439. doi:10. 1021/ef8005405

56. Tucker SA, Griffin JM, Acree WE, Zander M, Mitchell RH (1994) Spectroscopic properties of polycyclic aromatics compounds. Part IV: Effect of Solvent Polarity and Nitromethane on the Fluorescence Emission Behaviour of Select Bipolycyclic Aromatic Hydrocarbons. Appl Spectrosc 48:458-464 
57. Vargha-Butler EI, Zubovits TK, Budziak CJ, Neumann AW (1988) Surface tension of bitumen from contact angle measurements on films of bitumen. Energy Fuels 2:653-656

58. Williams RM, Verhoeven JW (1994) On the applicability of the Kasha-Vavilov rule to C60. Spectrochim Acta 50A:251-254

59. Yarranton HW et al (2013) On the size distribution of selfassociated asphaltenes. Energy Fuels 27:5083-5106. doi:10.1021/ef400729w

60. Yu X, Burnham NA, Mallick RB, Tao M (2013) A systematic AFM-based method to measure adhesion differences between micron-sized domains in asphalt binders. Fuel 113:443-447. doi:10.1016/j.fuel.2013.05.084

61. Zhang H, Yu J, Wang H, Xue L (2011) Investigation of microstructures and ultraviolet aging properties of organomontmorillonite/SBS modified bitumen. Mater Chem Phys 129:769-776. doi:10.1016/j.matchemphys.2011.04.078

62. Zhang L, Yang G, Wang J-Q, Li Y, Li L, Yang C (2014) Study on the polarity, solubility, and stacking characteristics of asphaltenes. Fuel 128:366-372. doi:10.1016/j.fuel.2014. 03.015 